\title{
AN INVESTIGATION OF EXTRACTED AGRICULTURE-FIBERS FOR CONCRETE PROPERTIES IMPROVEMENT
}

\author{
E. E. Ebrahiem \\ Chemical Engineering Department, Faculty of Eng., Minia University, Egypt. \\ M. M. Osama \\ Civil Engineering Department, Faculty of Eng., Minia University, Egypt.
}

\begin{abstract}
:
Agriculture residues like bagasse and rice straw are environmental problems. An investigation to use their fibers in cuncrete was studied. To convert such byproduct into useful cement-bonded composites was done by soaking them in lime solution (0$10 \%$ by weight) at $60^{\circ} \mathrm{C}$ for one hour to produce extracted fibers of higher flexibility. Different Parameters such as compressive strength, tension strength, composite density, water absorption, cracks due shrinkage and different percentage of fibers content (unextracted and extracted fibers) were considered. The optimum amount of fibers used was $2 \%$ of cement. Extracted bagasse fibers gave best results among other agricultural byproducts. Extracted bagasse has a positive effect on compressive strength (increased by $6-10 \%$ ), and on tension strength (increased by $50 \%$ ). The composite density was decreased by $6 \%$ and the water absorption was increased by $20 \%$. It was found that the best composite (using $1.5-2 \%$ by mass treated bagasse) was at density of $1.88 \mathrm{gm} / \mathrm{cm}^{3}$, absorption equal 12.7, compressive strength of $350 \mathrm{~kg} / \mathrm{cm}^{2}$ and tension strength equal $37.17 \mathrm{~kg} / \mathrm{cm}^{2}$.
\end{abstract}

Kevwords: Agriculture residues, Concrete, Fibers Extraction, Concrete properties, Properties Improvement.

\section{1- INTRODUCTION}

Asbestos a naturally occurring mineral fiber was used as a major source of reinforcement in fiber cement since 1970 [1,2]: A replacement due to the large capital cost of fiber was needed and, investment in existing manufacturing equipment; it was desirable that any replacement should be compatible with conventional processes. Fibers made from glass weal, carbon, a range of synthetic organic polymers were investigated $[3,4]$. Such fiber cements was chosen based on theoretical analysis because they possess homogeneous chemical composition, regular geometrical form and can be obtained with constant dimension. The prime objective of using fiber reinforcement too often was to achieve strength and not fracture toughness, however, the greater importance is placed on the enhancement of the tensile strain capacity of the matrix, the ability of the fibrous to inhibit unstable crack growth.

Natural fibers based on cellulose derived from trees, vegetable and grasses were a little cumbersome, they ine of varying chemical compositions, irregular in their geonietrical form and the dimensions of the fibers vary greatly. The choice of such natural plant fibers was mainly depend on the cheapness, availability and relatively low perförmance materials [4-7]. In addition panels and blocks prepared from natural plant fibers have the advantages of 
being light in weight and possess good thermal insulating properties [8]. The natural plant fibers (vellulsic fibers) are also effective in increasing the fracture energy of cementition matrices and in enhancing the tensile and flexural strength toughness and impact strength [9]. Plastic shrinkage cracks in mortar panels simulating cracking in concrete slable may impair the serviceability, durability or esthetics of concrete, and therefore of economic significance in the construction industry [9]. The aim of this study was to examines the effect of modified bagasse and rice straw fibers (extracted fibers) on the plastic shrinkage which reflect on the other properties of concrete.

\section{2-MATERIALS AND EXPERIMEMTS}

Two natural plants were used, namely bagasse and rice straw. Bagasse is residue left after crushing sugar cane for juice extraction. The outer layer of bagasse consists of a hard stiff fibrous substance while the inside part is soft material celled "pith" which is a non-fibrous material (35\%) having particlly no strength. Rice straw is the stamp part of the plant that was carrying rice, which is the fibrous part. The stamps are covered with very thin leaves of no value as fibrous material. Natural plants are composed aggregates of fibers cemented together with lignin. Modified fibers were obtained by extraction the lignin from fiber bundles by using weak alkali (lime). The procedure used was by soaking bagasse or rice straw in different lime solution $(0-10 \%$ by weight lime), heating for one hour at 60 ${ }^{\circ} \mathrm{C}$. The prepared slurry was washed well and defibrated in Hollander beater at $35 \%$ consistency. The non-fibrous material (pith of bagasse, or thin leaves of rice straw) was removed by screening on 100-mesh number, and the resulted extracted fibers were soft, flexible and suitable for fiber reinforced-cement composite.

Tivo sets of experiments were carried out, one prepared by using portland cement alone, the other one by using mortar with sand: cement ratio of $3: 1$ and with water cement ratio $(0.35-0.5)$. Samples were prepared by varying the fiber content $(0-4 \%)$. Effect of fiber content and method of treatment on the properties of concrete were determined. The following tests were carried out:

Plastic shrinkage cracks; compressive strength, tensile strength, density and water absorption. Tests are carried out according to standard procedures. Density, water absorption, compressive strength were measured by using cubes of $7 \times 7 \times 7 \mathrm{~cm}$ for master. Bending strength was measured in three points loading using a span of $200 \mathrm{~mm}$ by using $300 \times 150 \mathrm{x}$ $30 \mathrm{~mm}$ slabs. Plastic shrinkage cracking was measured by using lens, in a slab of $300 \times 300 \times 30 \mathrm{~mm}$ [12]. The test procedure proposed by Kraii [10] and refined by Shaeles and Hover [11] was used for evaluating the effects of fibers on plastic shrinkage cracking in concrete.

\section{3-RESULTS AND DISCUSSIONS}

The water to cement ratio studied gave workable mixes that range between $0.35-0.5$, an additional set of tests were determined at an optimum ratio of 0.35 for cement and 0.4 for mortar. These last ratios were used in the following studies. The effect of fiber content and the degree of treatment of fiber on the different properties cement composite were as follows:

\subsection{DENSITY:}

Fiber percentage, type and method of treatment influence the density of cement and mortar. Figure 1 and 2 shown this effect. The density was differing for each fiber content and it becomes lighter as the fiber content increases. The treatment of fiber with $\mathrm{CaO}_{2}$ has a very slight effect on the density. As shown in the figures, the density (after the addition of $2 \%$ mass of fiber) decreased by 1.735 $\mathrm{gm} / \mathrm{cm}^{3}$ and $1.685 \mathrm{gm} / \mathrm{cm}^{3}$ for bagasse and by $1.78 \mathrm{gm} / \mathrm{cm}^{3}$ and $1.74 \mathrm{gm} / \mathrm{cm}^{3}$ for rice straw (for cement and mortar respectively). 


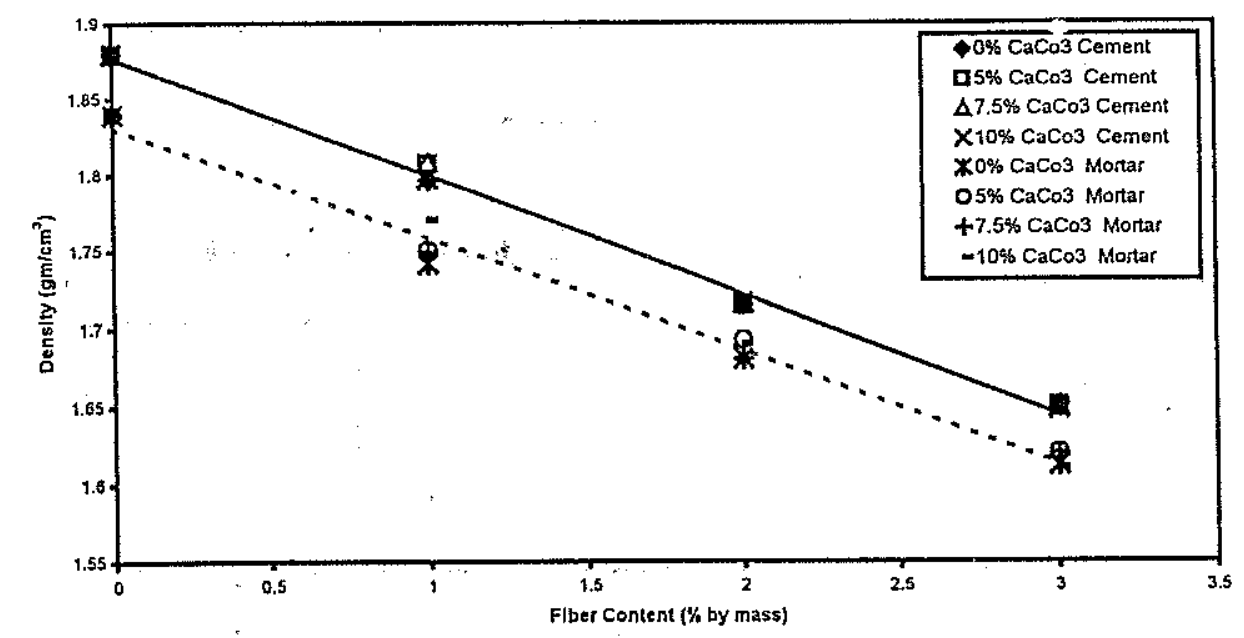

Figure 1: The Change of Cement Density Due to the Mixing of Different Bagasse Contents

(¿ Cement …....... Mortar).



Figure 2: The Effect of Cement Density Due to the Mixing of Different Rice Straw Contents

$$
\text { (- Cement ........... Mortar), }
$$

\subsection{WATER ABSORPTION:}

The influence of fiber type, fiber content and fiber treatment on water absorption of cement and mortar are shown in figures 3,7 . The results revealed that by increasing the fiber content, the water absorption increase. This is due to the porous structure of the fiber used that can absorb water. The increase in water absorption was about $16.5 \%$ for addition of $2 \%$ mass bagasse and $13 \%$ for the addition of $2 \%$ mass rice straw. 


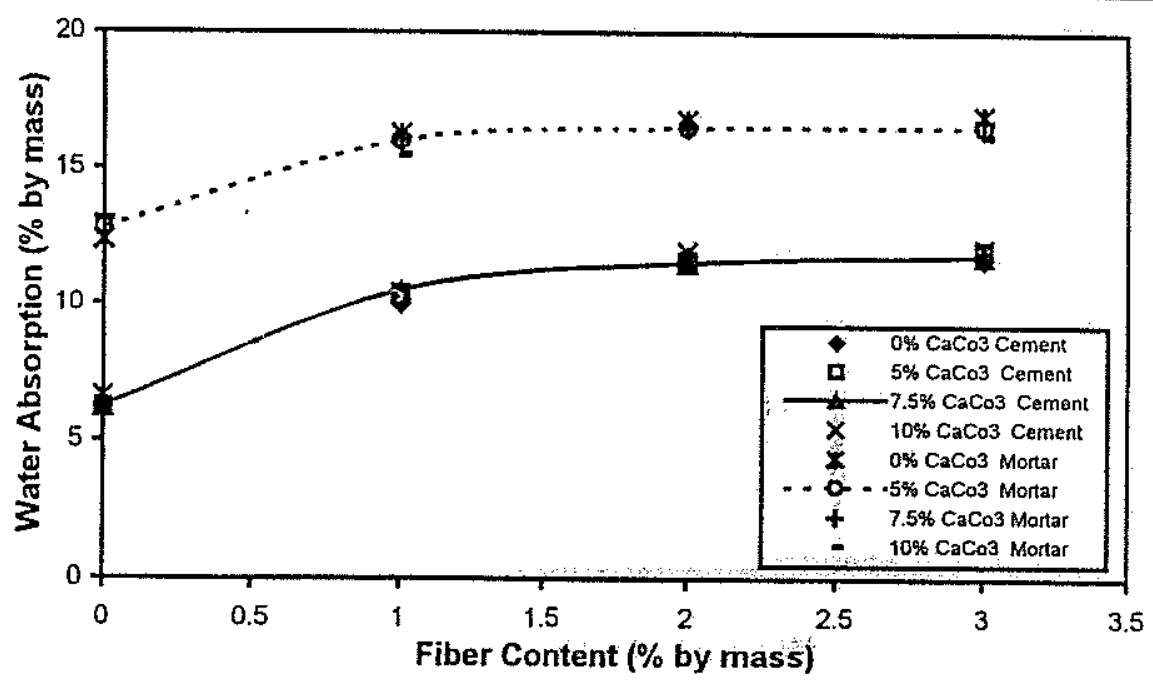

Figure 3: The Change of Water Absorption Due to the Mixing of Different Bagasse Contents.

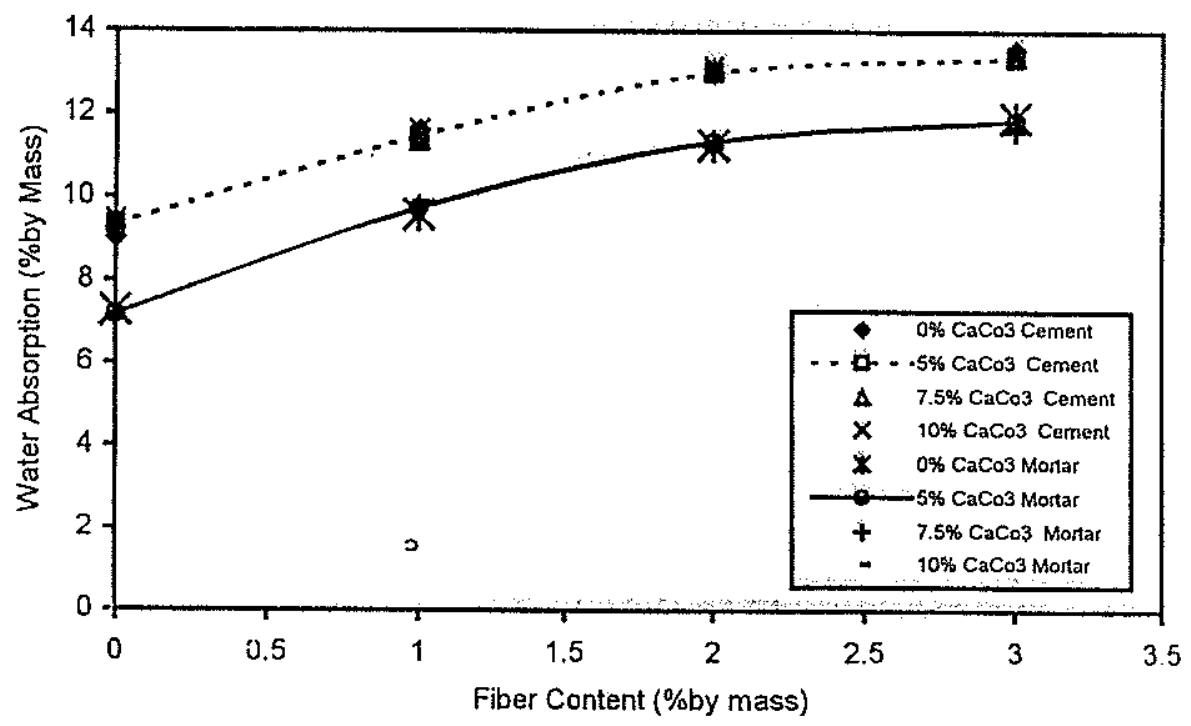

Figure 4: The Change of Water Absorption Due to the Mixing of Different Rice Straty Contents.

\subsection{COMPRESSIVE STRENGTH:}

Figures $5,6,7$ and 8 shown the compressive strength of a specimen of cement and mortar with different percentage of extracted bagasse and rice straw fibers and also unextracted ones. This compressive strength has a maximum value $b$ y the additional of $1-2 \%$ mass fiber while it differ according to the fiber type and the degree of fiber extraction. Th: average maximum value of compressiv. strength using bagasse was $291\left(\mathrm{~kg} / \mathrm{cm}^{2}\right)$ while the value for rice straw was 280 $\left(\mathrm{kg} / \mathrm{cm}^{2}\right)$. Generally the extracted- fiber give a hetter value than the unextracted one but the additional of bagasse give a fact that higher compressive strength than the rice straw. The increase in the compressive strength is due to the addition of fiber decrease the plastic shrinkage in the cement composite. 


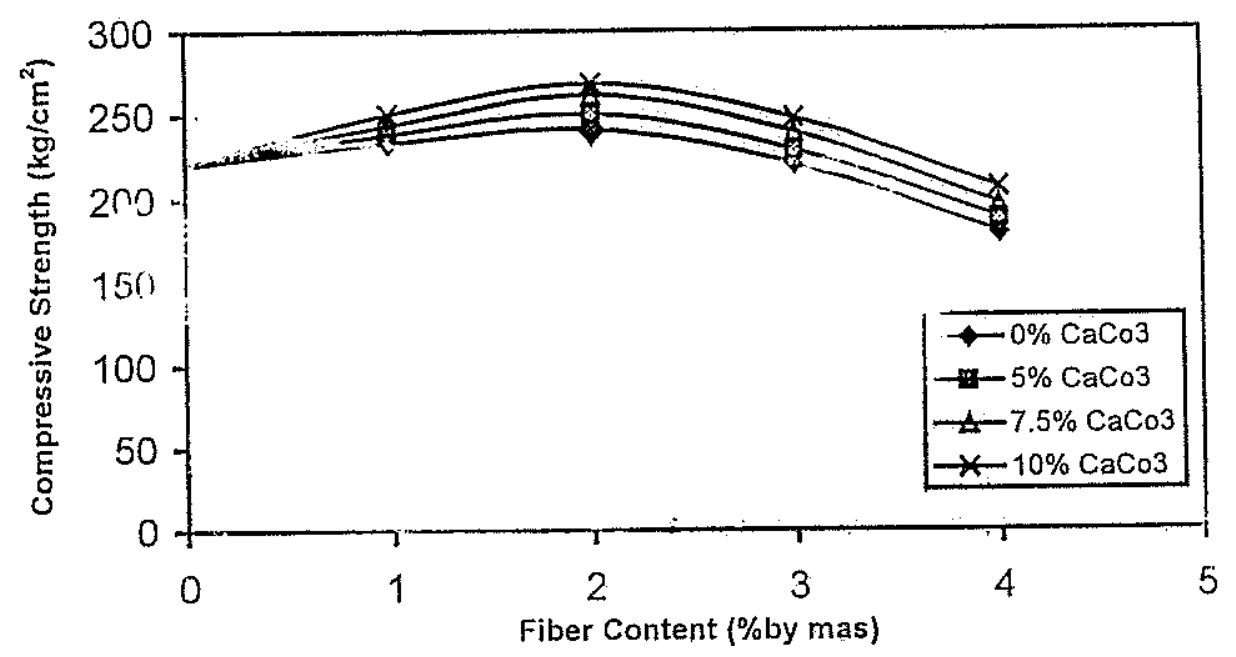

Figure 5: The Change of the Compressive Strength of Cement Due to the Mixing of Different Bagasse Contents (Cement).

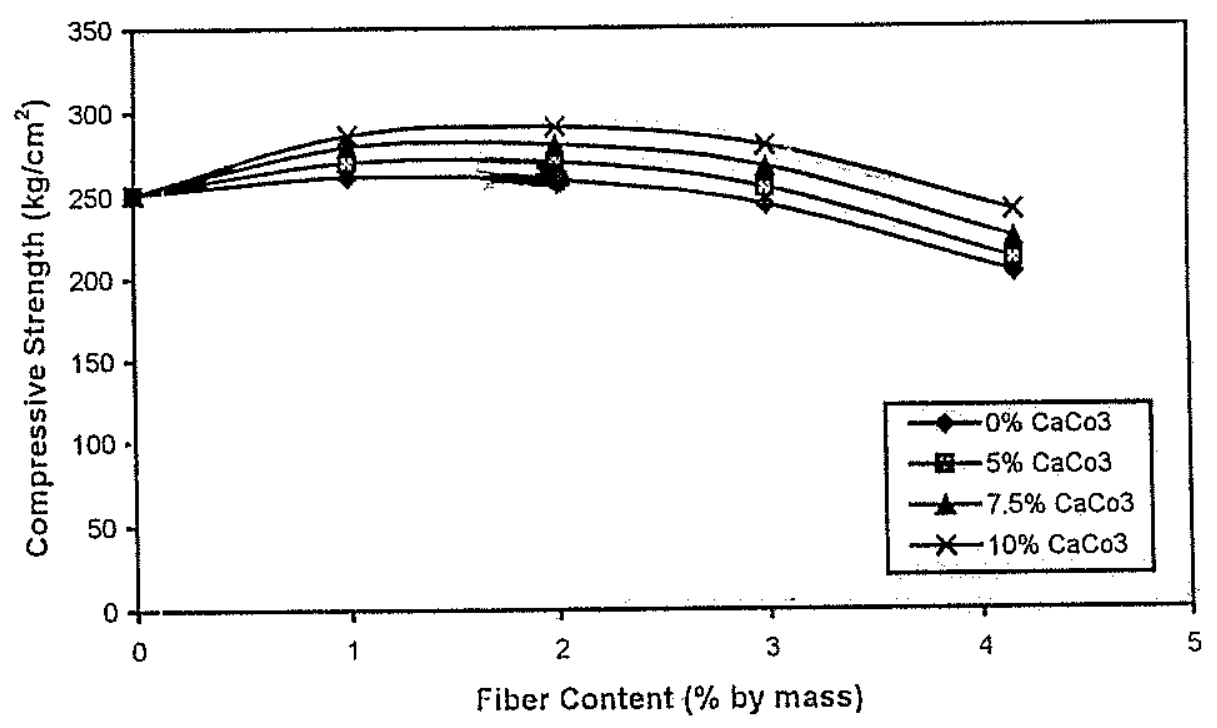

ligure 6: The Change of the Compressive Strength of Mortar Due to the Mixing of Different Bry:a, Contents (Mortar)

\subsection{MODULUS OF RAPTURE:}

Figure 9,10 showed that the modulus of rapture and mode of failure was significantly change in the specimen by the addition of different fiber percentage. The specimen with fiber has a ductile failure, since the specimen was holding together until the last fiber failed or pulled out (unlike the control specimen). Failure was more ductile for specimens with treatment fiber. 


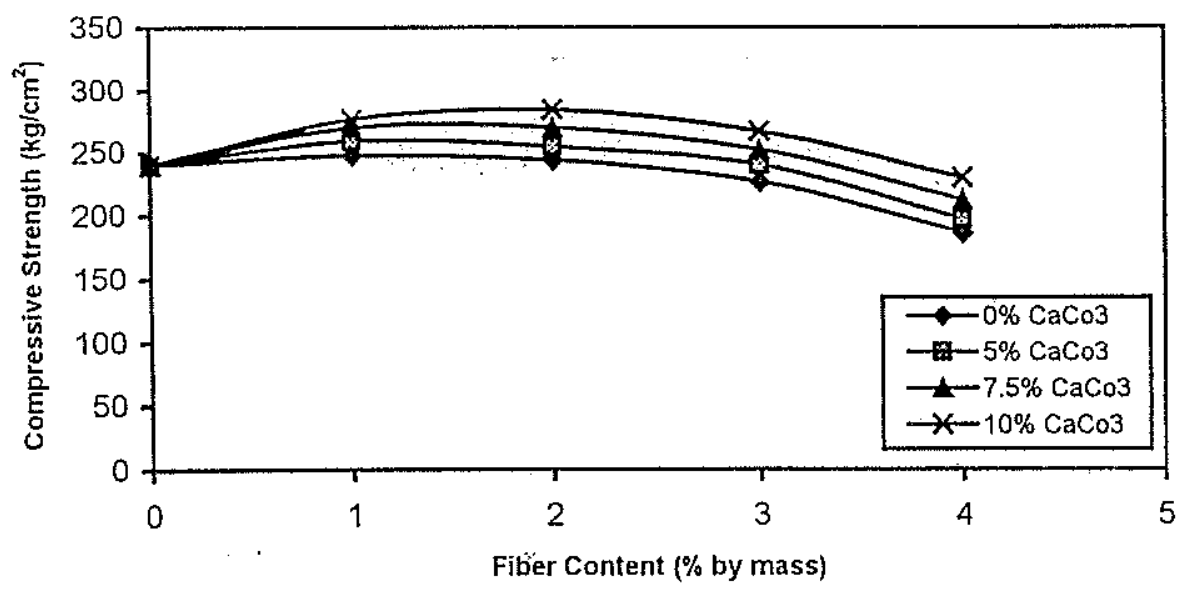

Figure 7: The Change of the Compressive Strength of Cement Due to the Mixing of Different Rice Straw Contents (Cement).

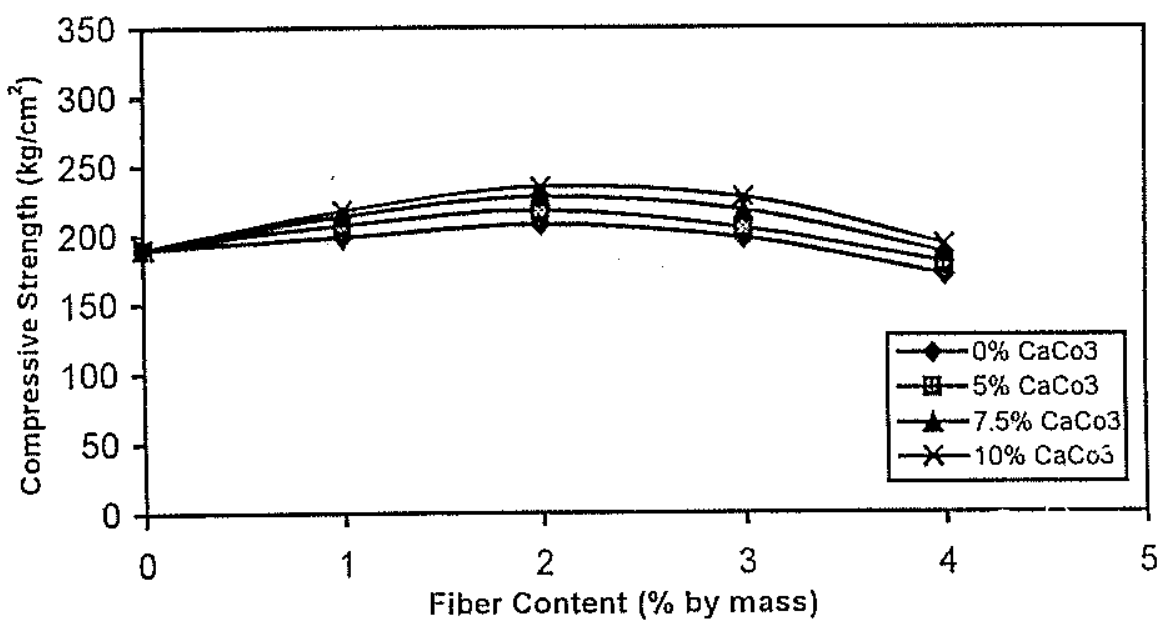

Figure 8: The Effect of Rice Straw Fiber on the Compressive Strength for mortar (Mortar).

\subsection{Plastic Shrinkage:}

Plastic Shrinkage cracks width and length was measured by method in [10] by using optical lens after 5 hours of adding the water total crack area was calculated by multiplying the width of each crack (the aveiage of 3 reading) by its length. Addition of very small percentage of
$(0.5 \%$ of bagasse reduces total plastic shrinkage cracking area and the cracking width very greatly (from $121 \mathrm{~mm}^{2}$ to 3.7 $\mathrm{mm}^{2}$ and from $1.1 \mathrm{~mm}$ to $0.15 \mathrm{~mm}$ ) This phenomena was observed by previous authors [12]. This effect is more clearly with the bagasse fiber more than the rice straw fiber as shown in the following table:

Table 1: Effect of Agriculture Residues on Plastic Shrinkage

\begin{tabular}{|c|c|c|c|c|}
\hline \multirow{2}{*}{ Fiber Content } & \multicolumn{2}{|c|}{ Total Crack Area mm } & \multicolumn{2}{c|}{ Max. Crack Width mm } \\
\cline { 2 - 5 } & Bagasse & Rice Straw & Bagasse & Rice Straw \\
\hline 0 & 121 & 151 & 1.1 & 1.25 \\
0.5 & 3.7 & 5.9 & 0.15 & 0.25 \\
1.5 & 2.1 & 4.1 & 0.15 & 0.25 \\
2 & 1.6 & 2.3 & 0.10 & 0.25 \\
\hline
\end{tabular}






Figure 9: The Effect of Bagasse Fiber on Modulus of Rapture.

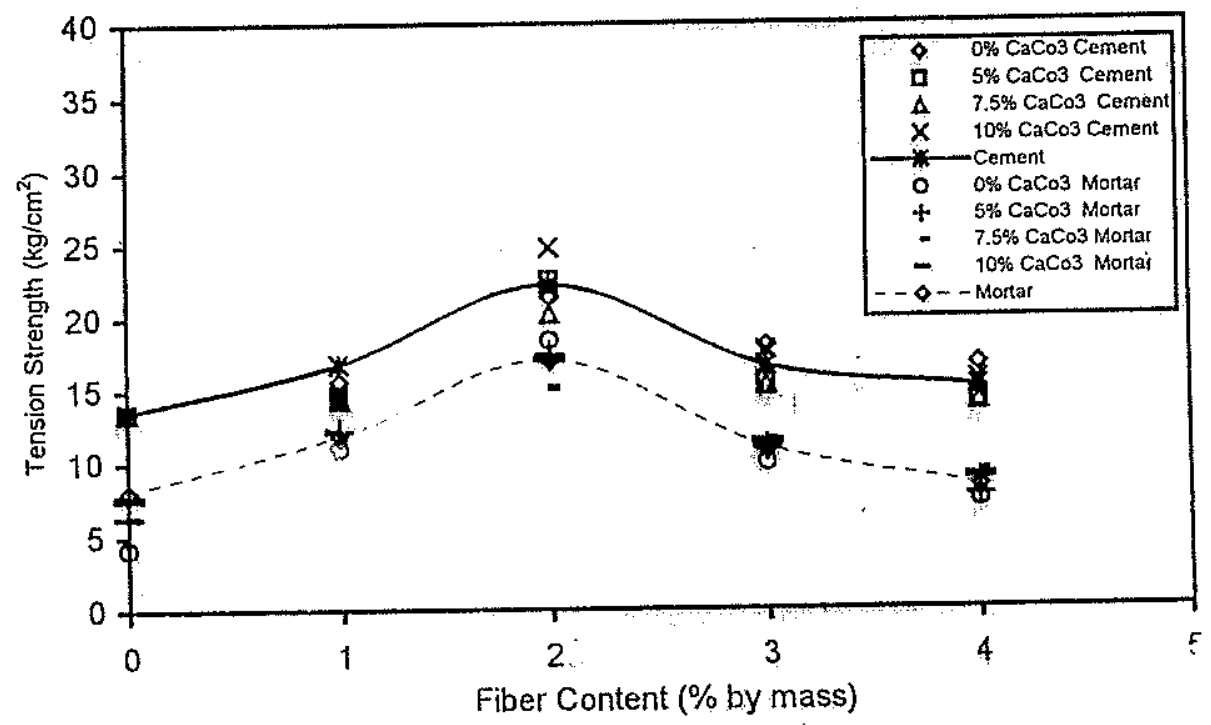

Figure 10: The Effect of Rice Straw Filuer on Modulus of Rapture.

\section{Conclusion}

Treatment of natural fibers (bagasse and rice straw) with lime to produce extracted fiber which is more flexible than unextracted showed great effect on some properties of concrete. The following are the effect of extracted fibers on the concrete:

1- The flexible natural fibers reduces plastic shrinkage greatly,

2- They increase modulus of rupture of concrete by about $50 \%$,
3- They increase compressive strength of concrete by $7-10 \%$ by addition of $1-2$ $\%$ fiber respectively,

1- Reduces the density of concrete by a value of $3 \%$ and $2 \%$ by adding $2 \%$ fiber of bagasse and rice straw respectively.

5- Increases, water absorption of concrete with $16.5 \%$ and $13 \%$ by adding $2 \%$ Tiber of bagasse and rice straw respectively: 


\section{REFERNCES}

[1] Hannent D. J., "Fiber Cements and Fiber Concrete", John Wiley \& Sons Chitchester, (19\%8).

[2] Piggot M. R., "Load Bearing Fiber Composites", Pergman Press, Toronto, (1980).

[3] Coak D. J., "Concrete and Cement Composites Reinforced with Natural Fibers", Construction Press Ltd., Lancaster, April (1980), pp. 99-114.

[4] Swamy R. N. (Ed.), "Natural Fiber Reinforced Cement and Concrete", Concrete Technology and Design, Blockie, London, Vol. 5, (1988).

[5] Swamy R. N. (Ed.), "New Reinforced Concrete", Concrete Technology and Design, Surrey University Press, Vol. 2, (1984).

[6] Gram H.E., "Durability of natural fibers in Concrete", Swedish Cement and Concrete Research Institute, Stockholm (1983).

[7] Lola C. R., "Fiber reinforced Concrete Roofing Technology Appraisal Report. In RILEMCRC86 (eds R.N. Swamy, R.L. Wagstaffe and D.R.
Oakley). Rilem Technical Committee 49-TER, paper 2-12, (1986).

[8] Aggarwal L.K., "Bagasse Reinforced Cement Composites", Cement Concerte Compositel, (1995), pp. 107-112.

[9] Soroushian P. and Mor. Kunte S., "Long-Term Durability and Moisture Sensitivity of Cellulose Fiber Reinforced Cement Composites", Edited by Swamy R.N., Rilen (1992).

[10] Kraai, Paul P., "A Proposed Test to Determine the Cracking Potential Due to Drying Shrinkage of Concrete" Concrete Construction, Vol. 30, No. 9 Sept. (1985), pp. 775-778.

[11] Christos A. S. and Keanneth C.H., "Influence of Mix Proportions and Construction Operations on Plastic Shrinkage Cracking in Thin Slabs", American Concrete Institute Materials Journal, Vol. 85, No. 6, (1988), pp. 495-504.

[12] Abdulrahman A., Faiz M., "Effect of Low Volume Fraction of Polypropylene Fiber on the Plastic Shrinkage Cracking", The $4^{\text {th }}$ Saudi Engineering Conference, Jeddah Saudi Arabia, Vol. 11, (1995), pp. 181-192. 